\title{
Survival From Severe Pandemic H1N1 in Urban and Rural Turkey: A Case Series
}

\author{
Cenk Kirakli MD, Dursun Tatar MD, Pinar Cimen MD, Ozlem Edipoglu MD, \\ Meral Coskun MD, Emel Celikten MD, and Ayse Ozsoz MD
}

\begin{abstract}
BACKGROUND: Pandemic influenza A (H1N1) was a serious health problem during the winter of 2009-2010 in Turkey. OBJECTIVE: To clarify the clinical and demographic characteristics of patients who needed intensive care in our region. METHODS: We conducted a prospective cohort study from November 2009 to February 2010 of demographic characteristics, clinical course, management strategies, 28-day mortality, and stay in the intensive care unit (ICU). RESULTS: During the study period, in our ICU we followed 18 patients (10 female) with H1N1. Their median (and IQR) age was 39 y (24-52 y), their median (and IQR) Acute Physiology and Chronic Health Evaluation (APACHE II) score was 16 (10-25), and 7 (39\%) of them lived in rural places. All 18 patients had acute lung injury (ALI) or acute respiratory distress syndrome (ARDS). The most common risk factors for severe H1N1 infection were obesity (33\%), COPD (16\%), and pregnancy (11\%). Thirteen patients (72\%) needed mechanical ventilation at ICU admission. Mortality was $50 \%(9 / 18)$ at day 28 . Significantly more survivors were urban dwellers than rural $(82 \%$ vs $0 \%, P<.001)$. There were also statistically significant differences between survivors and nonsurvivors in success of noninvasive ventilation, time to confirmation of the H1N1 virus after ICU admission, creatinine, lactate dehydrogenase, $\mathrm{pH}, \mathrm{P}_{\mathrm{aCO}}$, and $\mathrm{P}_{\mathrm{aO}} / \mathrm{F}_{\mathrm{IO}_{2}}$. CONCLUSIONS: The most common clinical presentation was ALI/ARDS in H1N1 patients who needed intensive care. Living in rural areas might have affected those patients' access to advanced ICU facilities and early ventilatory support. Failure of noninvasive ventilation, late diagnosis, late antiviral therapy, high APACHE II score, and living in a rural area were associated with mortality. Key words: pandemic influenza A; H1N1; intensive care; acute lung injury; ALI; acute respiratory distress syndrome; ARDS; critically ill; influenza; intensive care; pulmonary embolism. [Respir Care 2011;56(6):790-795. (C) 2011 Daedalus Enterprises]
\end{abstract}

\section{Introduction}

In April 2009, the United States Centers for Disease Control and Prevention reported the first 2 cases in the

Drs Kirakli, Tatar, Cimen, Edipoglu, Celikten, and Ozsoz are affiliated with the Intensive Care Unit; and Dr Coskun is affiliated with the Infectious Diseases Department, Izmir Training and Research Hospital for Thoracic Medicine and Surgery, Izmir, Turkey.

The authors have disclosed no conflicts of interest.

Dr Kirakli presented a version of this paper at the 13th Annual Congress of the Turkish Thoracic Society, held May 5-9, 2010, in Istanbul, Turkey.

Correspondence: Cenk Kirakli MD, Intensive Care Unit, Izmir Training and Research Hospital, 1671 Sokak No. 159 Daire: 535530 Karsiyaka, Izmir, Turkey. E-mail: ckirakli@hotmail.com.

DOI: $10.4187 /$ respcare.00988
United States of human infection with a novel influenza A (H1N1) virus. ${ }^{1}$ Soon after that, Perez-Padilla et al reported 18 patients with respiratory failure, hospitalized due to pneumonia and confirmed $\mathrm{H} 1 \mathrm{~N} 1$ infection. ${ }^{2}$ The disease spread rapidly to many countries all around the globe. In June 2009, the World Health Organization (WHO) declared the first influenza pandemic of the century and raised the pandemic alert from phase 5 (the virus has caused sustained community-level outbreaks in 2 or more countries in one WHO region) to phase 6 , which is the final alert phase and indicates that the virus has caused sustained community-level outbreaks in 2 or more countries in different WHO regions and a global pandemic is underway. ${ }^{3}$ As of June 2010, worldwide more than 214 countries, territories, and communities had reported laboratory-confirmed cases of pandemic influenza H1N1 2009, and there have been over 18,209 deaths. $^{4}$ 
On December 14, 2009, the Turkish Ministry of Health declared 415 deaths due to pandemic influenza A (H1N1) in Turkey. ${ }^{5}$ Some studies have described the characteristics of H1N1 patients admitted to intensive care units (ICU). ${ }^{6-9}$ Some countries, including Mexico, Canada, and Spain, have experienced large outbreaks, with critically ill patients exhibiting respiratory failure and acute respiratory distress syndrome (ARDS). We studied the demographic characteristics, clinical and radiological features, and outcomes of critically ill H1N1 patients in our ICU in Izmir, Turkey, from November 2009 through February 2010.

\section{Methods}

\section{Study Design}

This was a single-center observational cohort study. We prospectively collected data on all adult patients with confirmed H1N1 infection admitted to our ICU. The study hospital (474 beds) is in Izmir, the third-largest city in Turkey, and is the regional educational and research hospital, specializing in pulmonary diseases and thoracic surgery. The study was approved by our institutional review board. The informed-consent requirement was waived because the study was an observational cohort study and because of the severity of the situation affecting public health.

\section{Patients}

Only patients with confirmed pandemic influenza A (H1N1) infection were included. Nasopharyngeal swab specimens were obtained from patients with suspected H1N1 infection in the pulmonary ward either before or at ICU admission due to respiratory failure. These specimens were sent to one of 3 reference laboratories in Izmir for real-time polymerase-chain-reaction testing.

\section{Definitions}

- Urban area: Izmir plus the surrounding communities whose population (urban nucleus) is greater than 50,000

- Rural area: open country and settlements with fewer than 2,500 residents

- Acute lung injury (ALI) and ARDS: per the AmericanEuropean Consensus Conference criteria ${ }^{10}$

- Time to admission: time from the onset of symptoms to first admission in any healthcare facility

- Time to antiviral initiation: time from onset of symptoms to first antiviral drug dose

- Time to H1N1 confirmation: time from ICU admission to positive confirmation of H1N1 via nasopharyngeal swab

\section{Outcomes}

Our primary outcome was mortality at day 28 after the onset of critical illness. The secondary outcomes were the need for mechanical ventilation, presence of risk factors, and ICU stay.

\section{Data Collection}

The data were collected and recorded by us. We assessed severity of illness with the Acute Physiology and Chronic Health Evaluation (APACHE II) instrument. We created a standardized form for data collection that included demographics (eg, age, sex, smoking status, and place of residence), APACHE II score (calculated in the first 24 hours of ICU admission), comorbidities, symptoms related to the H1N1 infection, radiologic characteristics, laboratory findings, and arterial blood gas analysis results. We also recorded time of admission, antiviral initiation time, $\mathrm{H} 1 \mathrm{~N} 1$ confirmation time, risk factors for $\mathrm{H} 1 \mathrm{~N} 1$ infection, need for and type of mechanical ventilation, complications that developed in the ICU, mortality at day 28, and ICU stay.

\section{Statistical Analysis}

Continuous variables are expressed as medians and interquartile range (25th and 75th percentiles) and categorical variables as number and percent. Differences between groups were assessed with the Fisher exact test for categorical variables and the Mann-Whitney $U$ test for continuous variables. We performed survival analysis via Kaplan-Meier survival distribution. A $P$ value of $\leq .05$ was considered statistically significant.

\section{Results}

Forty-six patients with pandemic influenza A (H1N1) infection were admitted to our hospital during the study period. All of them had H1N1 confirmed via real-time polymerase chain reaction. Eighteen patients (39\%) were admitted to the ICU with severe respiratory failure due to ALI/ARDS and enrolled in this study. Their median and IQR age was 39 y (24-52 y). None of them had been vaccinated. Ten $(56 \%)$ were female. The patients presented at the hospital in a median and IQR $4.5 \mathrm{~d}(2-5 \mathrm{~d})$ after the onset of symptoms, and took their first antiviral drug dose $5 \mathrm{~d}(3-7 \mathrm{~d})$ after the onset of symptoms, which is well outside the recommended 48 hours. All the patients were treated with oseltamivir, $75 \mathrm{mg}$ twice a day. The most common symptoms were cough, fever, myalgia, headache, 
Table 1. Demographics of 18 Patients at ICU Admission

\begin{tabular}{lc}
\hline \hline Age, median (IQR), y & $39(24-52)$ \\
SOFA score, median (IQR) & $5(4-10)$ \\
APACHE II score, median (IQR) & $16(10-25)$ \\
Male, no. (\%) & $8(44)$ \\
Smoking history, no. (\%) & $7(39)$ \\
Signs and Symptoms, no. (\%) & \\
Cough & $18(100)$ \\
Fever & $16(89)$ \\
Myalgia & $9(50)$ \\
Headache & $8(44)$ \\
Sore throat & $5(28)$ \\
Vomiting & $3(17)$ \\
Diarrhea & $1(5)$ \\
Presence of Any Risk Factor, no. (\%) & $11(61)$ \\
Obesity & $6(33)$ \\
COPD & $3(16)$ \\
Pregnancy & $2(11)$ \\
Chronic cardiac disease & $2(11)$ \\
Hypertension & $2(11)$ \\
Mechanical ventilation needed at ICU admission, no. (\%) & $13(72)$ \\
\hline ICU = intensive care unit & \\
SOFA = sequential organ failure assessment & \\
APACHE = Acute Physiology and Chronic Health Evaluation & \\
\hline
\end{tabular}

sore throat, vomiting, and diarrhea. Table 1 shows their demographic and clinical characteristics.

All the patients had bilateral infiltrates on chest radiograph, with the involvement of predominantly 2/4 quadrants $(72 \%)$, and 2 patients had pulmonary embolism confirmed via computed tomogram. Eleven patients $(61 \%)$ had at least one risk factor for severe disease from H1N1 according to WHO criteria. ${ }^{11}$ Six patients (33\%) were obese (body mass index $>30 \mathrm{~kg} / \mathrm{m}^{2}$ ), 3 had COPD, 2 had congestive heart failure, 2 had diabetes mellitus, and 2 had hypertension. Two patients were pregnant: one was admitted to the ICU in early puerperium, and the other underwent Cesarean delivery while in the ICU.

Thirteen patients $(72 \%)$ had hypoxemic respiratory failure that did not resolve with supplemental oxygen, and they needed mechanical ventilation. Ten of them were treated initially with noninvasive ventilation (NIV), and seven $(70 \%)$ failed NIV and were intubated and ventilated with a low-tidal-volume strategy, in a pressure controlled mode. Four of the intubated patients needed prone positioning due to persistent hypoxemia. ${ }^{12}$

Secondary bacterial pneumonia developed in 4 patients in the ICU, and they underwent bronchoalveolar lavage with fiberoptic bronchoscopy. Two patients had methicillin-resistant Staphylococcus aureus, one had Acinetobacter baumannii, and one had Escherichia coli. One patient with methicillin-resistant $S$. aureus and the patient with A. baumannii developed severe sepsis and shock due to bacterial superinfection, and died. Seven patients needed vasopressors and/or inotropes, and four required continuous venovenous hemodiafiltration for acute renal failure.

Of the 18 patients, 9 survived to day 28. The mortality rate was $90 \%$ in the intubated patients. Between the survivors and nonsurvivors there were statistically significant differences in APACHE II score, H1N1 confirmation time, creatinine and lactate dehydrogenase, $\mathrm{pH}, \mathrm{P}_{\mathrm{aCO}_{2}}, \mathrm{P}_{\mathrm{aO}_{2}} / \mathrm{F}_{\mathrm{IO}_{2}}$. need for and type of mechanical ventilation, and ICU complications, including need for vasopressors, refractory hypoxemia, superinfection, and septic shock (Table 2). Patients in whom NIV succeeded were more likely to survive $(P=.001)$.

All 7 rural patients died, whereas 2 of the 11 urban patients died $(P<.001)$. Median APACHE II score was significantly higher in the rural patients (24 vs $12, P=.04$ ).

\section{Discussion}

To our knowledge, this is the first report of data on the characteristics of critically ill H1N1 patients in Turkey, in whom H1N1 predominantly affected young adults and women. The most common symptoms were cough, fever, myalgia, and headache. Critical illness occurred within the first week after the onset of symptoms. All the patients who needed intensive care had hypoxemia $\left(\mathrm{P}_{\mathrm{aO}_{2}}\right.$ / $\mathrm{F}_{\mathrm{IO}_{2}}<300 \mathrm{~mm} \mathrm{Hg}$ ), and $90 \%$ of the intubated patients died. Our measures of illness severity (APACHE II, severity of hypoxemia, $\mathrm{pH}$, and NIV failure), time to $\mathrm{H} 1 \mathrm{~N} 1$ confirmation, and rural dwelling were predictors of mortality.

Since the beginning of the outbreak there have been a few reports on $\mathrm{H} 1 \mathrm{~N} 1$ patients treated in the ICU. The mortality rates have ranged from $17 \%$ to $50 \% .6,8,9,13,14$ In our patients the overall mortality at day 28 was $50 \%$, which may be due to the lack of ICU facilities in rural Turkey, because $78 \%$ of the nonsurvivors were from rural areas. Critical care medicine is still not a specialty in Turkey, and most of the hospitals in the rural areas do not have optimal ICUs. Pulmonary physicians, anesthesiologists, and internal medicine specialists are in charge of the ICUs, but there is no standard fellowship program. Most of the critically ill patients are referred to the ICUs in the urban hospitals, because the rural hospitals lack experienced ICU staff and technical facilities such as advanced ventilators and monitoring systems. All our rural patients in this study were transferred to our hospital from rural hospitals, so they did not receive ICU treatment until they were at our hospital, which may have delayed antiviral therapy and other procedures, thus increasing the mortality in the rural patients. Additionally, our rural patients had much lower income than our urban patients, which might have affected their nutritional status and thus their immune status. NIV success/failure delineated the more severely ill patients (who failed NIV) from those with milder disease 
Table 2. Characteristics of Survivors and Nonsurvivors

\begin{tabular}{|c|c|c|c|}
\hline & $\begin{array}{l}\text { Survivors } \\
(n=9)\end{array}$ & $\begin{array}{c}\text { Nonsurvivors } \\
\quad(n=9)\end{array}$ & $P$ \\
\hline \multicolumn{4}{|l|}{ Demographics and Risk Factors } \\
\hline Age, median (IQR), y & $31(20-52)$ & $39(27-48)$ & 60 \\
\hline Male, no. (\%) & $2(22)$ & $6(67)$ & .58 \\
\hline Rural inhabitants, no. (\%) & $0(0)$ & $7(78)$ & $<.001$ \\
\hline Smoking history, no. (\%) & $2(22)$ & $5(56)$ & .14 \\
\hline Presence of any risk factor, no. (\%) & $4(44)$ & $7(78)$ & .14 \\
\hline Obesity, no. (\%) & $2(22)$ & $4(44)$ & .31 \\
\hline Body mass index, median (IQR), $\mathrm{kg} / \mathrm{m}^{2}$ & $25(23-27)$ & $29(28-33)$ & .08 \\
\hline \multicolumn{4}{|l|}{ Severity of Illness } \\
\hline Mechanical ventilation needed at ICU admission, no. (\%) & $4(44)$ & $9(100)$ & .008 \\
\hline APACHE II score, median (IQR) & $12(9-14)$ & $25(18-33)$ & $<.001$ \\
\hline NIV success, no. (\%) & $3 / 4(75)$ & $0 / 6(0)$ & .001 \\
\hline Duration of admission, median (IQR), d & $3(2-5)$ & $5(4-5)$ & .22 \\
\hline Time to antiviral initiation, median (IQR), d & $5(2.5-6)$ & $5(4-7)$ & .48 \\
\hline Time to H1N1 confirmation, median (IQR), d & $1(0-2)$ & $3(2-3)$ & .003 \\
\hline ICU stay, median (IQR), d & $8(5-9)$ & $6(5-7)$ & .48 \\
\hline Hospital stay, median (IQR), d & $16(11-22)$ & $7(7-10)$ & .003 \\
\hline \multicolumn{4}{|l|}{ Laboratory Values } \\
\hline White blood cells, median (IQR), cells $/ \mathrm{mm}^{3}$ & $7,900(3,900-12,000)$ & $8,500(4,800-12,700)$ & .79 \\
\hline Hemoglobin, median (IQR), mg/dL & $11(10-12)$ & $12(10-14)$ & 60 \\
\hline Hematocrit, median (IQR), \% & $35(33-37)$ & $36(33-41)$ & .43 \\
\hline Platelets, median (IQR), cells $\times 10^{3}$ & $252(202-386)$ & $204(54-267)$ & .26 \\
\hline C-reactive protein, median (IQR), $\mathrm{mg} / \mathrm{dL}$ & $11(5-24)$ & $15(11-26)$ & .32 \\
\hline Eosinophil count, median (IQR), cells $/ \mu \mathrm{L}$ & $70(50-80)$ & $75(25-220)$ & .81 \\
\hline Creatinine, median (IQR), mg/dL & $0.8(0.7-0.8)$ & $1.1(0.9-1.8)$ & .04 \\
\hline Lactate dehydrogenase, median (IQR), U/L & $287(201-516)$ & $736(418-2,277)$ & .04 \\
\hline Albumin, median (IQR), g/dL & $2.9(2.5-3.4)$ & $2.8(2.5-3.2)$ & .60 \\
\hline $\mathrm{pH}$, median (IQR) & $7.48(7.45-7.50)$ & $7.32(7.23-7.47)$ & .03 \\
\hline $\mathrm{P}_{\mathrm{aCO}_{2}}$, median (IQR), mm Hg & $31(26-36)$ & $38(36-49)$ & .02 \\
\hline $\mathrm{P}_{\mathrm{aO}_{2}} / \mathrm{F}_{\mathrm{IO}_{2}}$, median $(\mathrm{IQR}), \mathrm{mm} \mathrm{Hg}$ & $150(98-232)$ & $67(60-100)$ & .04 \\
\hline \multicolumn{4}{|l|}{$\begin{array}{l}\text { ICU }=\text { intensive care unit } \\
\text { APACHE }=\text { Acute Physiology and Chronic Health Evaluation } \\
\text { NIV }=\text { noninvasive ventilation }\end{array}$} \\
\hline
\end{tabular}

(who tolerated NIV). H1N1 confirmation time was also longer in nonsurvivors than in survivors, and later diagnosis might have affected the access time to advanced ICU care and procedures.

The overall NIV success rate in our patient group was $30 \%$. Rello and co-workers reported an NIV success rate of $25 \%$ in Spain. ${ }^{8}$ In other reports, from Canada and Utah, the NIV success rate was about $15 \% .{ }^{9}$ NIV predominantly benefits hypercapnic respiratory failure, although some studies have shown good results in hypoxemic patients also. ${ }^{15-17}$ The benefit of NIV was mostly in the subgroup of patients with severe community-acquired pneumonia: not in those with ARDS/ALI. ${ }^{16}$ A meta-analysis suggested that NIV did not decrease the intubation rate and that there was not enough evidence to support the use of NIV in ALI/ARDS patients. ${ }^{18}$ Recent research suggests that NIV benefits a small percentage of patients with ALI/ARDS due to H1N1, but the past high NIV failure rate should be kept in mind, and these patients should be closely monitored and intubated without delay if they clinically deteriorate. ${ }^{19}$

The H1N1 pandemic differed from earlier pandemics such as the H2N2 1889 Russian influenza pandemic, the H2N2 1957 Asian influenza pandemic, and the H3N2 1968 Hong Kong influenza pandemic, in which the infection was mostly among children and young adults, and the mortality was greatest in very young children and the elderly. ${ }^{20}$ In the H1N1 pandemic, severe illness requiring intensive care was predominantly in adults, 20-70 years of age. and the median age of nonsurvivors was only 39 years. The 1918 Spanish influenza pandemic was similar and was also caused by the H1N1 subtype. ${ }^{21}$ Most fatalities in the 1918 Spanish pandemic had secondary bacterial pneumonia and ARDS. It is still unknown why so many deaths 
occurred among the young and healthy. In the current H1N1 pandemic, people over age 70 were not so severely affected, which might be due to previous exposure to H1N1 viruses that circulated between 1918 and 1957.22

The most common underlying condition that correlated with severe H1N1 illness in our patients was obesity, with a rate of 33\%. Similar findings came from Mexico, Spain, and Canada. ${ }^{6-8}$ Primary risk factors were chronic lung disease, cardiac diseases, and pregnancy. However, besides those underlying conditions, 7 of our 18 patients were previously healthy adults, and two of them died.

The recent H1N1 pandemic seemed to be associated with a high incidence of severe disease and substantial mortality in pregnant women, whose hospital admission rate was 4 times higher than that of the general population. ${ }^{23}$ Other reports found higher ICU admission due to H1N1 in pregnant women than in nonpregnant women. ${ }^{24,25}$ Clinicians caring for pregnant women should be alert for influenza-like symptoms when a pandemic virus is locally present, and should encourage pregnant women to be vaccinated and to begin empirical antiviral therapy immediately if influenza symptoms occur, irrespective of negative diagnostic tests.

In several countries, pulmonary embolism has been present in $\mathrm{H} 1 \mathrm{~N} 1$ patients at admission or arose during ICU stay, ${ }^{26-28}$ and two of our patients had pulmonary embolism confirmed via contrast-enhanced computed tomogram.

\section{Conclusions}

Pandemic influenza A (H1N1) is especially dangerous for people with obesity, chronic diseases, or pregnancy, but is also dangerous even in healthy young adults. National H1N1 databases should be created in countries that do not yet have them. Patients, especially those from rural areas, who show clinical deterioration and hypoxemia should immediately be directed to an ICU with advanced invasive and NIV facilities. Specialists should closely monitor these patients and start antiviral therapy immediately, regardless of the diagnostic tests, as recommended in the WHO guidelines. ${ }^{11}$ Successful NIV application can decrease the mortality rate and is a first-line intervention, but if NIV fails during the first hours, the patient should be intubated without delay. Complications and high mortality rate should be kept in mind, particularly in patients from rural areas, young obese patients, women in early puerperium, and pregnant women. Vaccination is the best protection during a viral pandemic.

\section{ACKNOWLEDGMENTS}

We thank the American Thoracic Society's MECOR (Methods in Epidemiologic, Clinical and Operations Research) Program, and Phil Hopewell MD, in particular, for stimulating our interest in this research and advice on the manuscript.

\section{REFERENCES}

1. Swine influenza A (H1N1) infection in two children-Southern California, March-April 2009. MMWR Morb Mortal Wkly Rep 2009; 58(15):400-402.

2. Perez-Padilla R, de la Rosa-Zamboni D, Ponce de Leon S, Hernandez M, Quiñones-Falconi F, Bautista E, et al. Pneumonia and respiratory failure from swine-origin influenza A (H1N1) in Mexico. N Engl J Med 2009;361(7):680-689.

3. Chan M. Transcript of statement by Margaret Chan, Director-General of the World Health Organization. June 11, 2009. http://www.who.int/ mediacentre/influenzaAH1N1_presstranscript_20090611.pdf. Accessed April 11, 2011.

4. World Health Organization. Pandemic (H1N1) 2009 - update 106. June 25, 2010. http://www.who.int/csr/don/2010_06_25/en/index. html. Accessed April 11, 2011.

5. Kilian C. Turkey: "Over 600” H1N1 deaths. H5N1 news and resources about influenza, infectious diseases, and public health. March 9, 2010. http://crofsblogs.typepad.com/h5n1/2010/03/turkeyin-talks-to-return-unused-swine-flu-vaccines.html. Accessed April 11, 2011.

6. Kumar A, Zarychanski R, Pinto R, Cook DJ, Marshall J, Lacroix J, et al. Critically ill patients with 2009 influenza A(H1N1) infection in Canada. JAMA 2009;302(17):1872-1879.

7. Dominguez-Cherit G, Lapinsky SE, Macias AE, Pinto R, EspinosaPerez L, de la Torre A, et al. Critically Ill patients with 2009 influenza A(H1N1) in Mexico. JAMA 2009;302(17):1880-1887.

8. Rello J, Rodriguez A, Ibanez P, Socias L, Cebrian J, Marques A, et al. Intensive care adult patients with severe respiratory failure caused by influenza A (H1N1) in Spain. Crit Care 2009;13(5):R148.

9. Miller RR 3rd, Markewitz BA, Rolfs RT, Brown SM, Dascomb KK, Grissom CK, et al. Clinical findings and demographic factors associated with intensive care unit admission in Utah due to 2009 novel influenza A (H1N1) infection. Chest 2010;137(4):752758.

10. Bernard GR, Artigas A, Brigham KL, Carlet J, Falke K, Hudson L, et al. The American-European Consensus Conference on ARDS. Definitions, mechanisms, relevant outcomes, and clinical trial coordination. Am J Respir Crit Care Med 1994;149(3 Pt 1):818-824.

11. World Health Organization Global Alert and Response (GAR). Clinical management of human infection with pandemic (H1N1); revised guidance. November 2009. http://www.who.int/csr/resources/ publications/swineflu/clinical_management/en. Accessed on April 11, 2011.

12. The Acute Respiratory Distress Syndrome Network. Ventilation with lower tidal volumes as compared with traditional tidal volumes for acute lung injury and the acute respiratory distress syndrome. N Engl J Med 2000;342(18):1301-1308.

13. Kopel E, Amitai Z, Grotto I, Kaliner E, Volovik I. Patients with pandemic $(\mathrm{H} 1 \mathrm{~N} 1)$ in intensive care units, Israel. Emerg Infect Dis 2009;16(4):720-721.

14. Lai AR, Keet K, Yong CM, Diaz JV. Severe H1N1-Associated acute respiratory distress syndrome: a case series. Am J Med;123(3):282$285 ; \mathrm{e} 282$.

15. Meduri GU, Turner RE, Abou-Shala N, Wunderink R, Tolley E. Noninvasive positive pressure ventilation via face mask. First-line intervention in patients with acute hypercapnic and hypoxemic respiratory failure. Chest 1996;109(1):179-193.

16. Ferrer M, Esquinas A, Leon M, Gonzalez G, Alarcon A, Torres A. Noninvasive ventilation in severe hypoxemic respiratory failure: a randomized clinical trial. Am J Respir Crit Care Med 2003;168(12): 1438-1444.

17. Antonelli M, Conti G, Rocco M, Bufi M, De Blasi RA, Vivino G, et al. A comparison of noninvasive positive-pressure ventilation and 


\section{Survival From Severe Pandemic H1N1 in Urban and Rural Turkey}

conventional mechanical ventilation in patients with acute respiratory failure. N Engl J Med 1998;339(7):429-435.

18. Agarwal R, Reddy C, Aggarwal AN, Gupta D. Is there a role for noninvasive ventilation in acute respiratory distress syndrome? A meta-analysis. Respir Med 2006;100(12):2235-2238.

19. Ramsey C, Funk D, Miller R, Kumar A. Ventilator management for hypoxemic respiratory failure attributable to H1N1 novel swine origin influenza virus. Crit Care Med 2010;38(4):e58-e65.

20. Cunha BA. Influenza: historical aspects of epidemics and pandemics. Infect Dis Clin North Am 2004;18(1):141-155.

21. Morens DM, Fauci AS. The 1918 influenza pandemic: insights for the 21st century. J Infect Dis 2007;195(7):1018-1028.

22. Gill PW, Murphy AM, Cunningham AL. Influenza A(H1N1): a widening spectrum? Med J Aust 1991;155(6):362-367.

23. Lapinsky SE. H1N1 novel influenza A in pregnant and immunocompromised patients. Crit Care Med;38(4 Suppl):e52-e57.
24. Creanga AA, Johnson TF, Graitcer SB, Hartman LK, Al-Samarrai T, Schwarz AG, et al. Severity of 2009 pandemic influenza A (H1N1) virus infection in pregnant women. Obstet Gynecol;115(4): 717-726.

25. 2009 pandemic influenza A (H1N1) in pregnant women requiring intensive care - New York City, 2009. MMWR Morb Mortal Wkly Rep;59(11):321-326.

26. Intensive-care patients with severe novel influenza A (H1N1) virus infection-Michigan, June 2009. MMWR Morb Mortal Wkly Rep 2009;58(27):749-752.

27. Agarwal PP, Cinti S, Kazerooni EA. Chest radiographic and CT findings in novel swine-origin influenza A (H1N1) virus (S-OIV) infection. AJR Am J Roentgenol 2009;193(6):1488-1493.

28. Hospitalized patients with novel influenza A (H1N1) virus infection: California, April-May, 2009. MMWR Morb Mortal Wkly Rep 2009; 58(19):536-541. 